\title{
Effects of Andrographis paniculata Extract on Toll- Like Receptor-4 (TLR4) Expression and Aorta Calcification in Rats Exposed to Cigarette Smoke
}

\author{
Made Bagus Adipermana ${ }^{1}$, I Nyoman Wiryawan', Wayan Aryadana', \\ I Gde Raka Widiana', I Gusti Kamasan Nyoman Arijana, \\ Made Satria Yudha Dwangga ${ }^{1}$ \\ ${ }^{1}$ Department of Cardiology and Vascular Medicine, Faculty of Medicine, Udayana University / Sanglah General \\ Hospital, Bali, Indonesia. \\ ${ }^{2}$ Department of Internal Medicine, Faculty of Medicine, Udayana University / Sanglah General Hospital, Bali, \\ Indonesia. \\ ${ }^{3}$ Department of Histology, Faculty of Medicine, Udayana University / Sanglah General Hospital, Bali, \\ Indonesia. \\ Corresponding Author: Made Bagus Adipermana
}

\begin{abstract}
Introduction: Smoking has been associated with morbidity and cardiovascular events. Administration of antioxidants can prevent aortic calcification and reduce levels of atherosclerosis markers caused by cigarette exposure. Andrographis paniculata, with the main ingredient of Andrographolide, has antioxidant, anti-inflammatory and effects on the cardiovascular system.

Methods: This study is an experimental study with a randomized post-test control group design to determine the effect of Andrographis paniculata extract on aortic abnormalities in rats. Samples were randomly divided into two groups: the control group, which was given standard feed and exposure to cigarette smoke, and the treatment group, which was given standard feed, exposure to cigarette smoke, and Andrographis paniculata extract.
\end{abstract}

Results: TLR4 expression in the control group (mean $41.50 \pm 4.17$ ), the first treatment group (mean $30.75 \pm 3.24$ ), the second group (mean $15.25 \pm 3.01$ ), the third group (mean $9.75 \pm$ 4.65). The Shapiro Wilk normality test showed that the data were normally distributed $(\mathrm{P}>$ $0.05)$ with homogeneous data variance $(\mathrm{P}>$ $0.05)$. The analysis was continued with One Way Anova and found a significant difference between groups $(\mathrm{P}=0.000)$. The aortic calcification in control group (mean $1.80 \pm$
0.616 pixel percentage); group 1 (means $1.00 \pm$ 0.48 pixel percentage), group 2 (mean $0.54 \pm$ 0.34 pixel percentage), group 3 (mean $0.24 \pm$ 0.16). In the Shapiro Wilk normality test, all data of aortic calcifications were normally distributed $(\mathrm{P}>0.05)$ with inhomogeneous data variance $(\mathrm{P}<0.05)$. The analysis continued with One Way Anova, and there were significant differences between groups $(\mathrm{P}=0.001)$.

Conclusion: Giving Andrographis paniculata extract to rats exposed to cigarette smoke decreased TLR4 expression and reduce the incidence of aortic calcification.

Keywords: Andrographis paniculata, calcification, TLR4

\section{INTRODUCTION}

Vascular calcification has been associated with morbidity and cardiovascular events such as atherosclerotic, myocardial infarction, coronary heart disease, and ischemic vascular disease.[1,2] Factors that trigger the induction of calcification include an inflammatory process in the blood vessels, the release of ROS in blood vessels due to an inflammatory process caused by smoking. The immune response, stress on the endothelium, and local induction of blood vessels such as OxLDL, inflammatory 
cytokines, and hypoxia can induce vascular calcification. [3,4]

TLR4 is a transmembrane protein and is a member of the pattern recognition receptor (PRR) that can recognize proinflammatory pathogens and play an essential role in atherosclerosis. TLR4 can recognize molecular forms of substances that invade both exogenously and endogenously in blood vessels.[5]

Administration of antioxidants can prevent aortic calcification and reduce levels of atherosclerosis markers caused by cigarette exposure. Andrographis paniculata, with the main ingredient of Andrographolide, has antioxidant, antiinflammatory and effects on the cardiovascular system. [6,7] Andrographolide showed the antiatherosclerosis effect of Andrographis paniculata also as an anti-inflammation and had a potent hypolipidemic effect by lowering total cholesterol levels such as triglycerides, HDL, and LDL.[6,7] Andrographis paniculata is also known to be able to reduce inflammation and is said to have antioxidant properties by preventing the production of free radicals. [4,8]

The purpose of this study was to prove whether the administration of Andrographis paniculata extract could reduce the expression of Toll Like Receptor-4 in rats exposed to cigarette smoke and could reduce the incidence of aortic calcification in rats exposed to cigarette smoke.

\section{METHODS}

This study is a collaborative research, an experimental study with a randomized post-test control group design to determine the effect of Andrographis paniculata extract on aortic abnormalities in rats. The research was conducted at the Integrated Biomedical Laboratory, Faculty of Medicine, Udayana University. With a population of male Swiss Webster (Mus musculus) rats exposed to cigarette smoke. With the inclusion criteria of rats aged 8-10 weeks, bodyweight 20-30 grams, healthy rats (active and not disabled). With the exclusion criteria of rats not actively moving, disabled rats, rats died during the study, the weight of the rats decreased (the weight of the rats became less than 20 grams). Samples were randomly divided into two groups: the control group, which was given standard feed and exposure to cigarette smoke, and the treatment group, which was given standard feed, exposure to cigarette smoke, and Andrographis paniculata extract. All data collected in each group were then analyzed using the SPSS program.

\section{RESULTS}

A total of 32 samples were tested for TLR4 and aortic calcification at the end of the study, divided into four groups: the control group with exposure to cigarette smoke and the treatment group with exposure to cigarette smoke and Andrographis paniculata extract.

a. The P0 group (control group) was given standard feed and exposure to kretek cigarette smoke for 60 days.

b. Group P1 (treatment group), was given standard feed, exposure to kretek cigarette smoke, and Andrographis paniculata extract at a dose of $18 \mathrm{mg} / \mathrm{kg} \mathrm{BW}$ for 60 days.

a. Group P2 (treatment group) was given standard feed, exposure to kretek cigarette smoke, and Andrographis paniculata extract at a dose of $29 \mathrm{mg} / \mathrm{kg} \mathrm{BW}$ for 60 days.

b. The P3 group (treatment group) was given standard feed, exposure to kretek cigarette smoke, and Andrographis paniculata extract at a dose of $40 \mathrm{mg} / \mathrm{kg}$ BW for 60 days.

Furthermore, the euthanasia process was carried out in rats by dissection of the neck of the rats. After euthanasia, the rats were surgically removed, and tissue was taken from the rat aortic tissue covering the aortic root to the aortic arch. Furthermore, a cross-section of the specimen was made for analysis in the form of TLR4 expression and also aortic calcification. The data were obtained, then we analyzed the data 
Made Bagus Adipermana et.al. Effects of andrographis paniculata extract on toll-like receptor-4 (TLR4) expression and aorta calcification in rats exposed to cigarette smoke.

normality test, homogeneity, and comparability.

\section{TLR4 Expression}

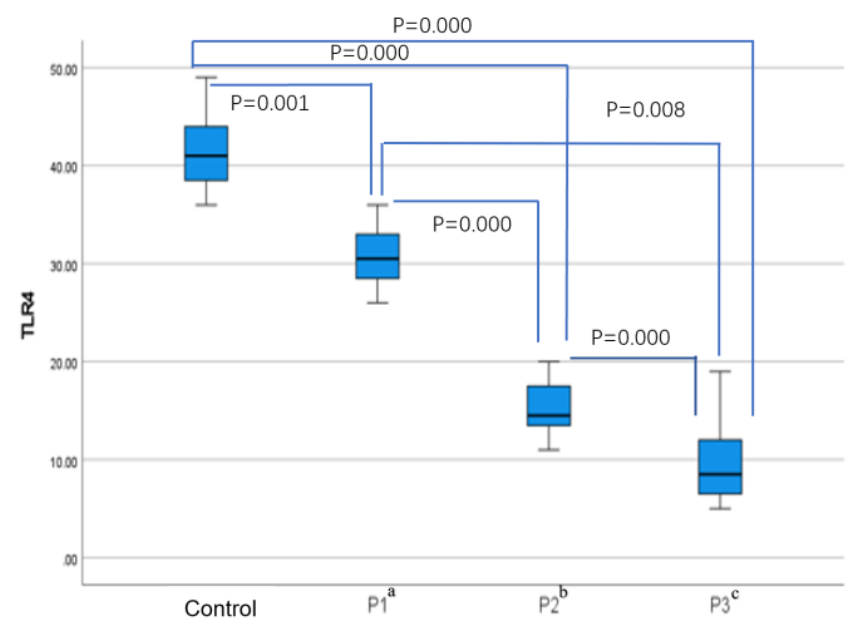

Graph 1. Box Plot Graph of Comparison of TLR4 Expression Means in Each Group

Based on the analysis, TLR4 expression in the control group (mean 41.50 \pm 4.17 ), the first treatment group (mean $30.75 \pm 3.24$ ), the second group (mean $15.25 \pm 3.01$ ), the third group (mean $9.75 \pm$ 4.65). The Shapiro Wilk normality test showed that the data were normally distributed $(\mathrm{P}>0.05)$ with homogeneous data variance $(\mathrm{P}>0.05)$. The analysis was continued with One Way Anova and found a significant difference between groups $(\mathrm{P}=$ $0.000)$.
Furthermore, post hoc analysis was carried out using the Post hoc LSD analysis test. In this test, it was found that there was a significant difference in TLR4 expression between the control group and all treatment groups $(\mathrm{P}<0.05)$. When examined between treatment groups, it was found that there were significant differences between treatment group 1 and treatment group 2 and between treatment group 2 and treatment group 3.

\section{Aorta Calcification}

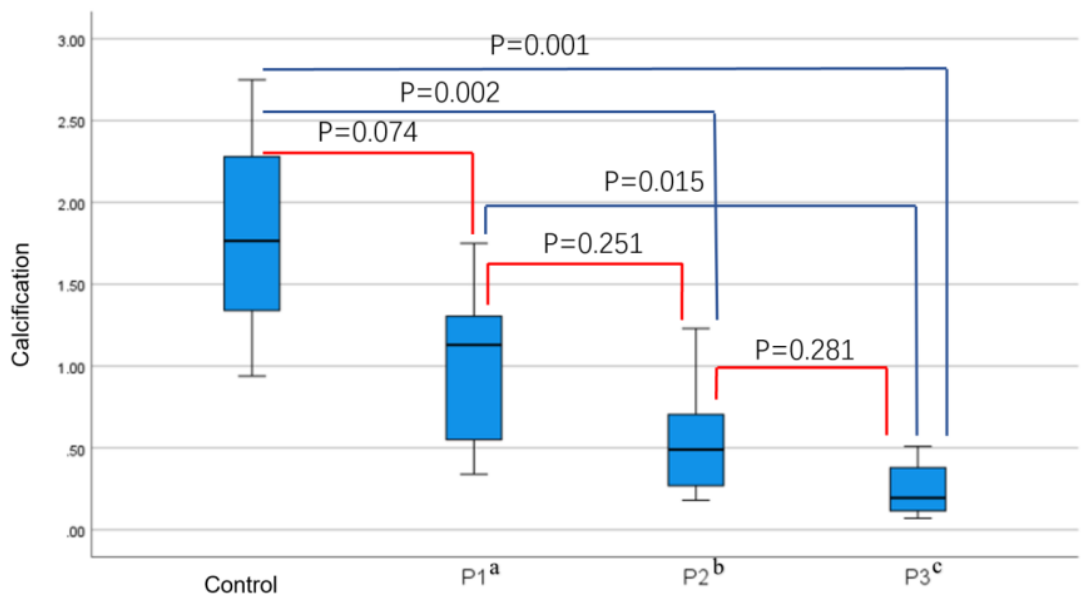

Graph 2. Box Plot Graph of Average Aortic Calcification in Each Group. $P 1=$ treatment one; $P 2=$ treatment two; $P 3=$ treatment three. The treatment was exposure to cigarette smoke and Andrographis paniculata extract at a dose of $18 \mathrm{mg} / \mathrm{kg}$ BW. treatment in the form of exposure to cigarette smoke and extracts of Andrographis paniculata at a dose of $29 \mathrm{mg} / \mathrm{kg} \mathrm{BW}$. The treatment was exposure to cigarette smoke and Andrographis paniculata extract at a dose of $40 \mathrm{mg} / \mathrm{kg} \mathrm{BW}$. 
Aortic calcification in rats is caused by calcium deposition in the rat's aorta. The amount of calcium deposit was calculated with the histopathological examination by the Von Kossa staining protocol. The rats then went to euthanasia and surgery by the digital analysis method. Each slide of the aorta was photographed with an objective magnification of 40 times with an Optilab Pro camera and an Olympus Cx41 microscope. The amount of calcium was calculated as a percentage of pixels compared to the pixels of the entire aortic tissue, and the results can be seen in graph 2.

From this analysis, the aortic calcification in control group (mean $1.80 \pm$ 0.616 pixel percentage); group 1 (means $1.00 \pm 0.48$ pixel percentage), group 2 (mean $0.54 \pm 0.34$ pixel percentage), group 3 (mean $0.24 \pm 0.16$ ). In the Shapiro Wilk normality test, all data of aortic calcifications were normally distributed $(\mathrm{P}>$ $0.05)$ with inhomogeneous data variance $(\mathrm{P}$ $<0.05)$. The analysis continued with One Way Anova, and there were significant differences between groups $(\mathrm{P}=0.001)$.

Based on the post hoc analysis using the Post hoc Tamhane test, there were significant differences in aortic calcification between the control group and treatment group 2 and treatment group $3(\mathrm{P}<0.05)$. However, there was no significant difference between treatment group 2 and treatment group 3 .

\section{DISCUSSION}

Smoking can induce oxidative stress that can activate the endothelium, activate inflammatory signals, macrophages, and platelets formation. This can trigger endothelial damage, tissue remodeling, aortic calcification, and prothrombotic processes. $[9,10]$

TLR4 expression in the control group was higher than all treatment groups. It can be concluded that the administration of Andrographis paniculata extract decreased TLR4 expression with a tendency for its effect to increase with increasing dose. The dose of Andrographis paniculata extract in treatment group $3(40 \mathrm{mg} / \mathrm{kg} \mathrm{BW})$ has the highest TLR4 reduction effect. TLR4 is a member of the pattern recognition receptor (PRR) that can recognize this pathogen and is essential in the process of atherosclerosis.[11] TLR4 is not only expressed in the early stages of pathogen recognition in an inflammatory process but is also expressed to play a role in various stages of the atherosclerotic process. The release of Nuclear factor-kB (NFkB) and TLR4 activates the transcription and secretion of proinflammatory genes such as interleukins (IL), tumor necrosis factor (TNF), colonystimulating factor, lymphokines, monokines, chemokines, and also interferon (IFN- $\alpha$ and IFN- $\beta$ ).[12,13] These proinflammatory genes increase the expression of adhesion molecules (selectin, vascular cell adhesion molecule-1) and intercellular adhesion molecule $\quad-1 \quad$ (ICAM-1). The proinflammatory genes recruit and migrate inflammatory cells to the vascular wall and accelerate atherosclerosis formation.[14] TLR4 binds to various types of ligands (LPS, Fibronectin EDA, HSP, LDL), which will signal proinflammatory cells (monocytes, macrophages, dendritic cells) that express TLR4 and play a role in various stages of atherosclerosis.[15,16]

The use of Andrographis paniculata extract has been widely used in research for various types of treatment. The extract was shown to be significant in inhibiting lipid peroxidation in rats can reduce total cholesterol, triglycerides, and LDL (Warditiani et al 2017) and can inhibit platelet aggregation in rats by increasing cyclic GMP/PKG and inhibiting the p38MAPK/HO cascade. -NF- $\square$ B-ERK2 on platelets. $[6,17,18]$ In this study, the Andrographis paniculata extract was shown to decrease the expression of TLR4 with a decreasing effect starting to appear in treatment group 1, namely at a dose of 18 $\mathrm{mg} / \mathrm{kg} \mathrm{BW}$, and there was a tendency for effect to increase with increasing dose. It was found that the dose of Andrographis 
paniculata extract in treatment group 3 (40 $\mathrm{mg} / \mathrm{kg} \quad \mathrm{BW}$ ) gave the highest TLR4 reduction effect. Until this study, no other studies examined the effect of the administration of Andrographis paniculata extract on the reduction of TLR4 expression.

From this analysis, the aortic calcification in the control group was higher than all treatment groups. There were significant differences in aortic calcification between the control group and treatment group 2 and treatment group 3. This indicates that the dosage of Andrographis paniculata extract $29 \mathrm{mg} / \mathrm{kg}$ BW gave an effect in decreasing aortic calcification and without further reduction with increasing the dose given.

The mechanism of how the administration of Andrographis paniculata extract can reduce the expression of TLR4 is thought to be through various pathways, such as those submitted by several studies, showing the antioxidant activity Andrographis paniculata, which play a role in preventing atherosclerosis. Research stated that the administration of Andrographolide, the active compound of Andrographis paniculata can reduce inflammatory mediators and prevent apoptosis in rats through the inhibition of TNF-, IL-1 $\beta$, and NO production.[19] Another study showed that Andrographolide reduced oxidative stress injury in RAW 264.7 cultured cells treated with cigarette extract via an inhibitory mechanism of SIRT1/ERK signaling. In addition, it was also stated that Andrographis paniculata has an anti-inflammatory effect through the inactivation of NF-B, where Andrographolide can activate PP2A.[20] PP2A dephosphorylates p65 Ser(536), which can reduce translocation of NF-kB and reduce NF-kB binding. In the process of atherosclerosis, NF-B is the main pathway activated by increased expression of TLR4, which can further lead to increased cytokines and chemokines involved in the inflammatory process.[21]

\section{CONCLUSION}

Exposure to cigarette smoke has been shown to increase the expression of TLR4 and cause aortic calcification in rats. Giving Andrographis paniculata extract to rats exposed to cigarette smoke decreased TLR4 expression with a tendency for its effect to increase with increasing dose and reduce the incidence of aortic calcification

\section{Acknowledgement: None}

\section{Conflict of Interest: None}

\section{Source of Funding: None}

\section{Ethical Approval: Approved}

\section{REFERENCES}

1. Virmani R, Joner M, Sakakura K. Recent Highlights of ATVB. Arterioscler Thromb Vasc Biol. 2014 Jul 1;34(7):1329-32.

2. Budoff MJ, Young R, Burke G, Jeffrey Carr J, Detrano RC, Folsom AR, et al. Ten-year association of coronary artery calcium with atherosclerotic cardiovascular disease (ASCVD) events: the multi-ethnic study of atherosclerosis (MESA). Eur Heart J. 2018 Jul 1;39(25):2401-8.

3. O'Rourke C, Shelton G, Hutcheson JD, Burke MF, Martyn T, Thayer TE, et al. Calcification of Vascular Smooth Muscle Cells and Imaging of Aortic Calcification and Inflammation. J Vis Exp JoVE. 2016 May 31;(111).

4. Al Hariri M, Zibara K, Farhat W, Hashem Y, Soudani N, Al Ibrahim F, et al. Cigarette Smoking-Induced Cardiac Hypertrophy, Vascular Inflammation and Injury Are Attenuated by Antioxidant Supplementation in an Animal Model. Front Pharmacol. 2016;7:397.

5. Cole JE, Georgiou E, Monaco C. The Expression and Functions of Toll-Like Receptors in Atherosclerosis. Mediators Inflamm. 2010 Jun 24;2010:e393946.

6. Warditiani NK, Susanti NMP, Arisanti CIS, Putri NPRD, Wirasuta IMAG. Antidyslipidemia And Antioxidant Activity Of Andrographolide Compound From Sambiloto (Andrographis Paniculata) Herb. Int J Pharm Pharm Sci. 2017 Jul 1;59-65. 
7. Wu T, Peng Y, Yan S, Li N, Chen Y, Lan T. Andrographolide Ameliorates

Atherosclerosis by Suppressing ProInflammation and ROS GenerationMediated Foam Cell Formation. Inflammation. 2018 Oct;41(5):1681-9.

8. Awang K, Abdullah NH, Hadi AHA, Su Fong Y. Cardiovascular Activity of Labdane Diterpenes from Andrographis paniculata in Isolated Rat Hearts. J Biomed Biotechnol. 2012 Mar 28;2012:e876458.

9. Messner B, Bernhard D. Smoking and Cardiovascular Disease. Arterioscler Thromb Vasc Biol. 2014 Mar 1;34(3):50915.

10. Roy A, Rawal I, Jabbour S, Prabhakaran D. Tobacco and Cardiovascular Disease: A Summary of Evidence. In: Prabhakaran D, Anand S, Gaziano TA, Mbanya J-C, Wu Y, Nugent R, editors. Cardiovascular, Respiratory, and Related Disorders [Internet]. 3rd ed. Washington (DC): The International Bank for Reconstruction and Development / The World Bank; 2017 [cited 2021 Oct 17]. Available from: http://www.ncbi.nlm.nih.gov/books/NBK52 5170/

11. Kawai T, Akira S. The role of patternrecognition receptors in innate immunity: update on Toll-like receptors. Nat Immunol. 2010 May;11(5):373-84.

12. Tousoulis D, Oikonomou E, Economou EK, Crea F, Kaski JC. Inflammatory cytokines in atherosclerosis: current therapeutic approaches. Eur Heart J. 2016 Jun 7; 37(22):1723-32.

13. Kopitar-Jerala N. The Role of Interferons in Inflammation and Inflammasome Activation. Front Immunol. 2017;8:873.

14. Libby P. Inflammation in atherosclerosis. Arterioscler Thromb Vasc Biol. 2012 Sep;32(9):2045-51.

15. den Dekker WK, Cheng C, Pasterkamp G, Duckers HJ. Toll like receptor 4 in atherosclerosis and plaque destabilization. Atherosclerosis. 2010 Apr;209(2):314-20.

16. Howell KW, Meng X, Fullerton DA, Jin C, Reece TB, Cleveland JC. Toll-like receptor 4 mediates oxidized LDL-induced macrophage differentiation to foam cells. J Surg Res. 2011 Nov;171(1):e27-31.

17. Graham C. The effect of smoking on the cardiovascular system. Br J Card Nurs. 2013 Apr 1;8(4):174-9.

18. Jayakumar T, Hsieh C-Y, Lee J-J, Sheu J-R. Experimental and Clinical Pharmacology of Andrographis paniculata and Its Major Bioactive Phytoconstituent Andrographolide. Evid-Based Complement Altern Med ECAM. 2013;2013:846740.

19. Zhang J, Zhu D, Wang Y, Ju Y. Andrographolide Attenuates LPS-Induced Cardiac Malfunctions Through Inhibition of I $\mathrm{B}$ Phosphorylation and Apoptosis in Mice. Cell Physiol Biochem. 2015;37(4):1619-28.

20. Zhang X-F, Ding M-J, Cheng C, Zhang Y, Xiang S-Y, Lu J, et al. Andrographolide attenuates oxidative stress injury in cigarette smoke extract exposed macrophages through inhibiting SIRT1/ERK signaling. Int Immunopharmacol. 2020 Apr; 81:106230.

21. Hsieh CY, Hsu MJ, Hsiao G, Wang YH, Huang CW, Chen SW, et al. Andrographolide enhances nuclear factorkappaB subunit p65 Ser536 dephosphorylation through activation of protein phosphatase $2 \mathrm{~A}$ in vascular smooth muscle cells. J Biol Chem. 2011 Feb 25;286(8):5942-55.

How to cite this article: Adipermana MB, I Nyoman Wiryawan, Aryadana W et.al. Effects of andrographis paniculata extract on toll-like receptor-4 (TLR4) expression and aorta calcification in rats exposed to cigarette smoke. International Journal of Research and Review. 2021; 8(10): 540-545. DOI: https://doi.org/10. 52403/ijrr.20211068 